\title{
Parameter Identification for Thermo-Mechanical Constitutive Modeling to Describe Process-Induced Residual Stresses and Phase Transformations in Low-Carbon Steels
}

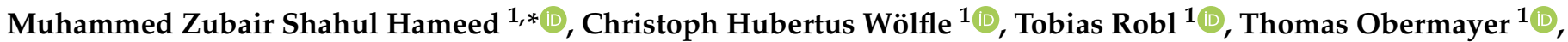

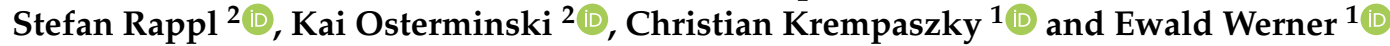 \\ 1 Institute of Materials Science and Mechanics of Materials, Technical University of Munich, Boltzmannstr. \\ 15, 85748 Garching, Germany; woelfle@wkm.mw.tum.de (C.H.W.); robl@wkm.mw.tum.de (T.R.); \\ obermayer@wkm.mw.tum.de (T.O.); krem@wkm.mw.tum.de (C.K.); werner@wkm.mw.tum.de (E.W.) \\ 2 Centre for Building Materials, Technical University of Munich, Franz-Langinger-Strasse 10, 81245 Munich, \\ Germany; stefan.rappl@tum.de (S.R.); kai.osterminski@tum.de (K.O.) \\ * Correspondence: zubair@wkm.mw.tum.de
}

Citation: Shahul Hameed, M.Z.; Wölfle, C.H.; Robl, T.; Obermayer, T.; Rappl, S.; Osterminski, K.;

Krempaszky, C.; Werner, E. Parameter Identification for Thermo-Mechanical Constitutive Modeling to Describe Process-Induced Residual Stresses and Phase Transformations in Low-Carbon Steels. Appl. Sci. 2021, 11, 550. https://doi.org/10.3390/ app11020550

Received: 17 December 2020

Accepted: 5 January 2021

Published: 8 January 2021

Publisher's Note: MDPI stays neutral with regard to jurisdictional clai$\mathrm{ms}$ in published maps and institutional affiliations.

Copyright: (C) 2021 by the authors. Licensee MDPI, Basel, Switzerland. This article is an open access article distributed under the terms and conditions of the Creative Commons Attribution (CC BY) license (https:// creativecommons.org/licenses/by/ $4.0 /)$.
Featured Application: Fatigue-resistant reinforcing bars in buildings and highway bridges where dynamic loading causes premature fatigue fractures.

Abstract: Reinforcing steel bars (rebars) are widely manufactured using the Tempcore ${ }^{\mathrm{TM}}$ process. Several studies have been conducted analyzing the effect of the heat treatment route on the strength and corrosion resistance of rebars, but knowledge of its effects on the residual stresses of the finished product are largely lacking. This paper presents experimental investigations to identify the material parameters necessary to simulate the Tempcore ${ }^{\mathrm{TM}}$ process using thermo-elasto-plastic constitutive modeling in order to study the generation of residual stresses during the manufacturing process. Mechanical parameters such as yield strength at elevated temperatures and elastic constants were determined experimentally. A continuous cooling transformation diagram needed to model the phase transformations was also identified and is presented here. Residual stress distributions in the surface region of the rebar were characterized using X-ray diffraction. Further characterizations of microstructure, chemical composition, and hardness were carried out. The constitutive modeling approach for the numerical simulation is briefly described for which the experimentally determined parameters are required as input.

Keywords: residual stress; constitutive modeling; quenching; Tempcore ${ }^{\mathrm{TM}}$ process; reinforcing steel

\section{Introduction}

Tempcore ${ }^{\mathrm{TM}}$ is the trademark for the heat treatment route that was developed in the 1970s by CRM Group and has since been widely used for the manufacturing of reinforcing steel bars (rebars) [1,2]. It is a quench and self-tempering thermo-mechanical process wherein the hot rolled rebars come out of the last hot-rolling mill at a temperature above $\mathrm{A}_{\mathrm{c} 3}$ at which the rebars are still in their austenitic state and then are rapidly quenched with water sprayed onto their surface at high volumetric flow rate. The outer layer of the rebar transforms from austenite to martensite up to a certain depth. The time of quenching and the volume of water sprayed are controlled to achieve the desired thickness of the outer martensitic layer for a given diameter of the rebar, and below this depth the core is still austenitic. The rebar is then left to cool in the cooling bed, where the core transforms to a ferrite and pearlite mixture while the heat dissipating from the core tempers the martensitic layer, hence the name Tempcore. The process is schematically presented in Figure 1. This composite nature of the rebar with an outer hard layer and a ductile inner core is achieved with a relatively simple heat treatment process that produces high-strength rebars that are bendable and weldable without the need for micro-alloying with $\mathrm{V}$ or $\mathrm{Nb}$ [1-3]. 


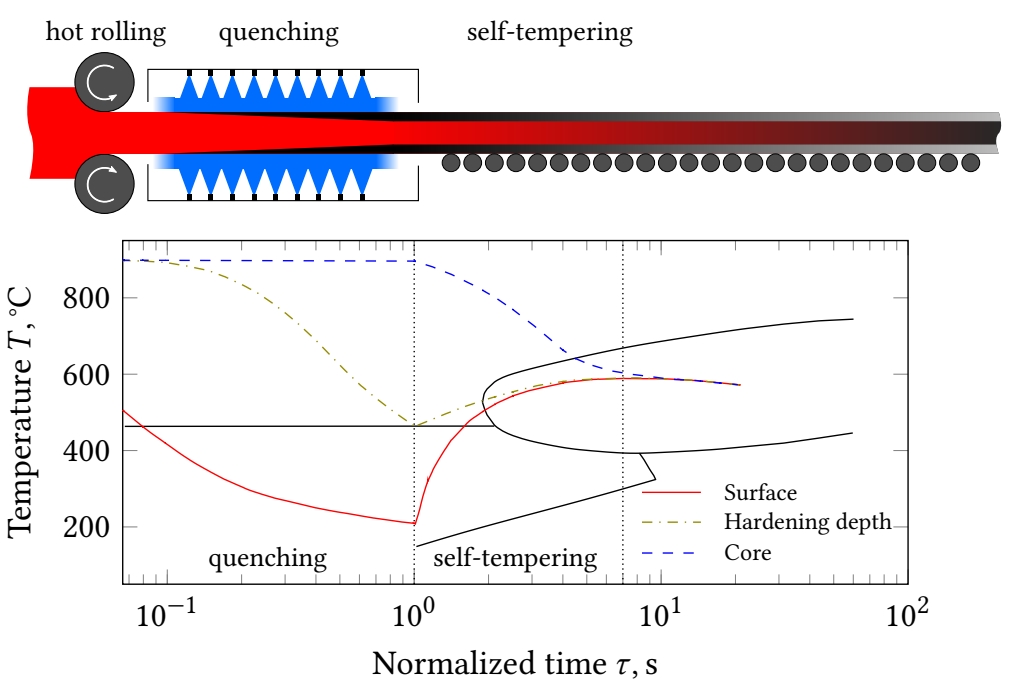

Figure 1. Schematic representation of the Tempcore ${ }^{\mathrm{TM}}$ process.

The Tempcore ${ }^{\mathrm{TM}}$ process often has been investigated from the point of view of strength and corrosion resistance [4-7], fatigue behavior during service [8], behavior at high temperatures [9], and effects of their geometry [10]. Very few studies could be found in the literature that investigate the residual stresses that are generated during the manufacturing process itself. The research project from which this report is extracted aims at understanding the links between fatigue performance and residual stresses in the rebars, with the goal to enhance their fatigue life. It is well established that macroscopic compressive surface residual stresses enhance the fatigue performance of the material by closing fatigue cracks that usually initiate near the surface. On the other hand, tensile residual stresses lead to premature failure of parts by aiding crack growth and could also lead to stress corrosion cracking [11,12]. In service, the residual stresses are superimposed with the external load stresses and can be either beneficial or sometimes catastrophically detrimental by lowering the stresses at which cracks initiate to dangerously low levels [13].

\subsection{Origin of Residual Stresses during Quenching}

The residual stresses in the finished product are a consequence of the asynchronous thermal shrinkage and phase transformation of the core and the surface regions. During quenching all materials are exerted to shrinkage stresses since the surface always cools faster than the core. Additionally, if phase transformations occur during quenching, transformation stresses ensue as well and superimpose on the aforementioned shrinkage stresses. In order to understand the origin of the residual stresses during quenching and thereby the factors that affect it, a closer look at the generation of these two types of stress is necessary. The top part of Figure 2 shows the cooling curves of the surface and the core of a cylinder during quenching $\left(T^{\mathrm{s}}, T^{\mathrm{c}}\right)$ together with the yield stress, $R_{\mathrm{y}}$ of these regions, which depends on the temperature and hence on process time and is assumed to be the same for compression and tension. For simplicity, only the longitudinal stress component is shown, although criteria for plastic flow also consider the tangential and radial components [14-16].

Concentrating only on the shrinkage stresses on the left side, the surface cools faster than the core at the initial stage of the quench. This results in longitudinal tensile stresses at the surface, whereas the core experiences longitudinal compressive stresses. As long as there is no plastic deformation, these stresses will be balanced at the end of the process with no residual stresses, as can be seen in the middle part of Figure 2a. Usually, however, these shrinkage stresses exceed the yield stress of the material shown as a gray shaded area in the figure. This is promoted by the low yield stress at high temperatures where the temperature gradients are very high $[10,15]$. Therefore, the material flows plastically leaving residual stresses at the end as shown in the bottom part of Figure 2a. Upon further 
cooling the core temperature falls rapidly while the surface gradually reaches the temperature of the cooling medium, thus reducing the magnitude of the shrinkage stresses and eventually reversing their signs. The plastic stretching of the surface causes compression at the surface and vice versa in the core. Once the temperature balance is established, the cylinder is left with compressive stresses at the surface and tensile stresses in the core due to the shrinkage stresses.
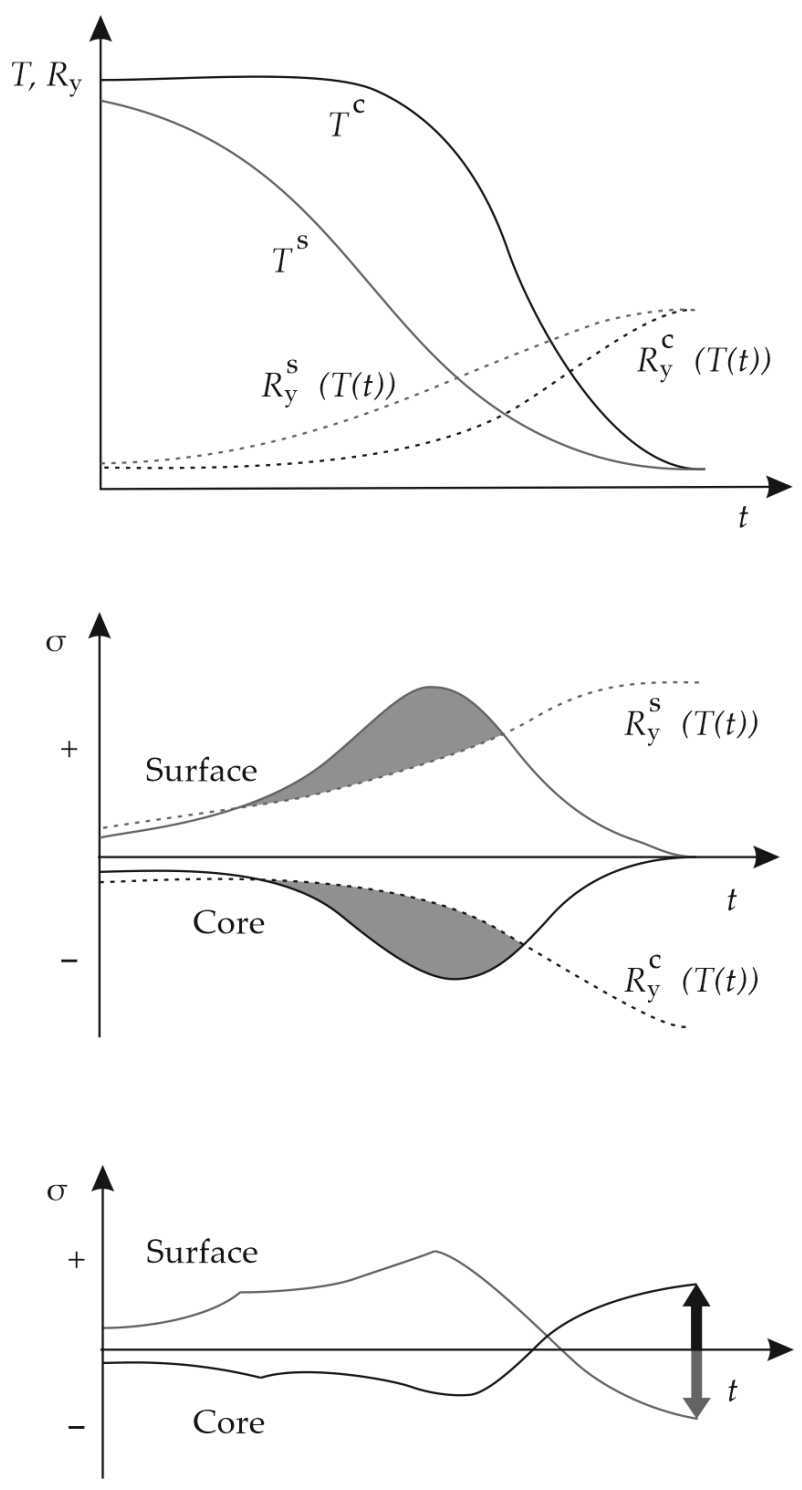

(a) Shrinkage stresses
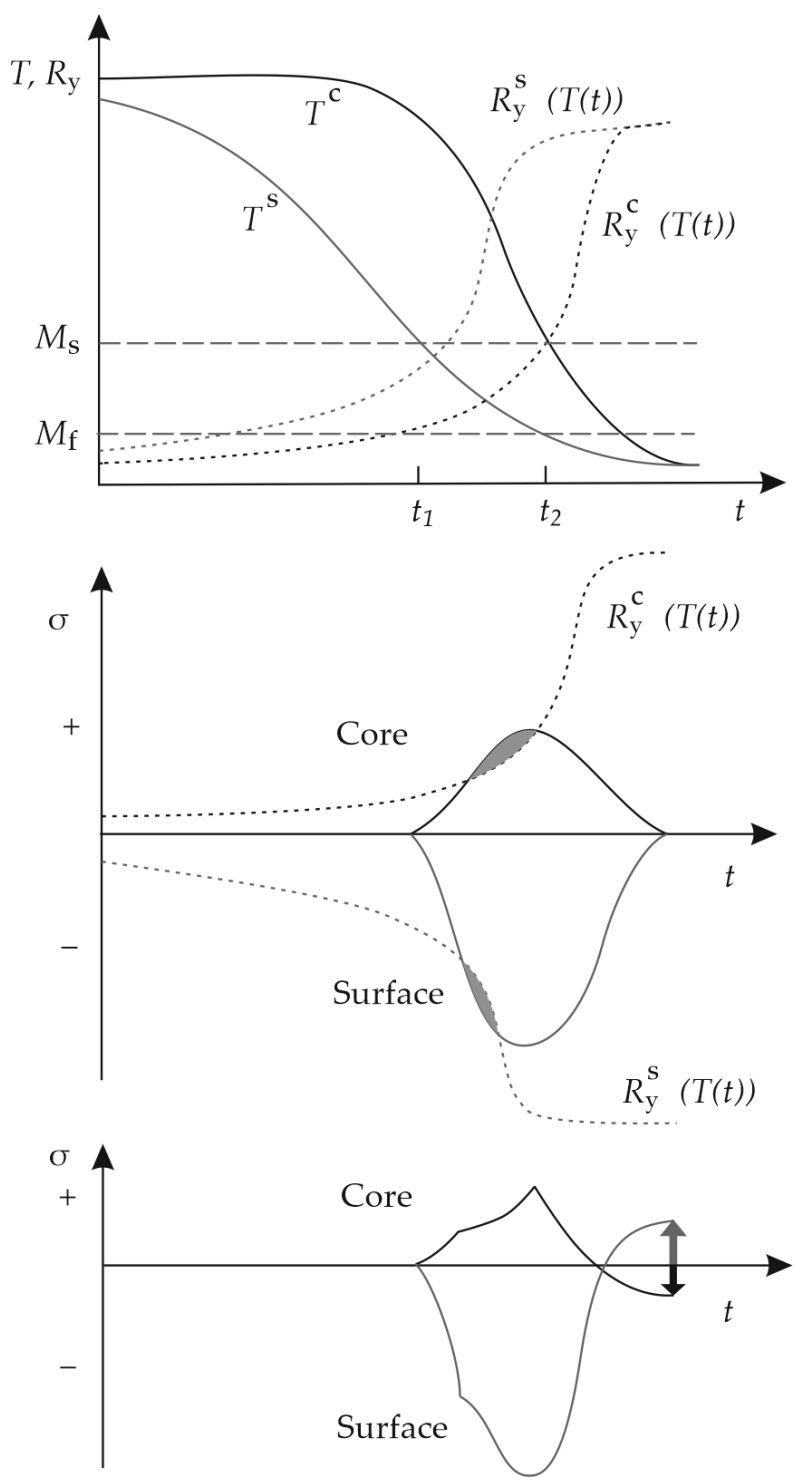

(b) Transformation stresses

Figure 2. Origin of longitudinal residual stress component during quenching of cylinders. Adapted from [14].

If the phase transformation in the material is to be considered, the same line of reasoning could be laid out for pure transformation stresses ignoring the thermal shrinkage stresses and transformation plasticity. The top part of Figure $2 \mathrm{~b}$ shows the cooling curves of the surface and the core of the cylinder, the martensite start and finish temperatures, $M_{\mathrm{S}}$ and $M_{\mathrm{f}}$, and the temperature-dependent yield stress of the material. Upon reaching $M_{\mathrm{S}}$ it is assumed that the whole material transforms into martensite, which occurs at times $t_{1}$ at the surface and $t_{2}$ in the core. The volume expansion associated with the austenite to martensite transformation, which is ca. $3.4 \%$ for $0.19 \%$ C steel [17], leads to compressive stresses arising near the surface compensated by tensile stresses in the core as shown in the middle part of Figure $2 \mathrm{~b}$. Once the core reaches $M_{\mathrm{S}}$ and starts to transform and expand, the stresses are reduced in both regions. Due to the transformation into much harder 
martensite, the yield stress curves undergo a much larger increase in magnitude than in the case of mere thermal shrinkage as shown in Figure 2a, left. The plastic flow occurring due to the transformation stresses exceeding the yield point (shown in gray) results in volume incompatibilities between the core and the surface at the end of the cycle. This leads to residual stresses, which are shown at the bottom of Figure $2 b$ by arrows, which are reversed in sign compared to the left image.

Combining these two types of stress by simple superposition is not accurate, since the material has deformed plastically. The fundamental concept from this discussion is, however, helpful in understanding the factors involved in solving such problems and the material parameters required for modeling such a quenching process successfully. It is clear that the yield stress of the material at high temperatures determines plastic flow and has to be quantified. The relative position of the time in which the transformation initiates and ends at the surface and in the core significantly influences the magnitude as well as the sign of the final residual stresses [14].

To the best of the authors' knowledge these parameters are not available in literature for the B500B alloy, which constitutes a large fraction of commercially available rebars and, hence, have to be determined experimentally. Some attempts have been made to predict the strength and transformation temperatures with models and theoretical calculations [5]. The thermal history or the cooling curve across the cross section of the bar during quenching and tempering is, however, impractical and prohibitively expensive to obtain directly from the manufacturing facility, if for this purpose the production of large tonnages has to be stopped. Therefore, several studies have been conducted to predict the transient temperature profile across the cross-section of the rebar with computational fluid dynamics simulations of the coolant coupled to the heat transfer problem in the rebar $[5,18,19]$.

In summary, the following facts are important to consider. The plastic deformation determines the magnitude of the residual stresses. The temperature difference between the surface and the core is dependent on the following factors: the starting temperature of the quenching process, the diameter, the heat transfer coefficient, and the thermal properties of the material. The residual stresses are larger in magnitude if the yield strength at high temperature is very low, due to larger plastic deformation. Finally, the residual stresses greatly depend on the relative initiation time of the transformation in the surface and core regions.

The phenomena that were neglected in the above discussion for simplicity need to be considered for solving real problems. The material as a whole will not transform into martensite, but rather a mixture of all the phases including ferrite, pearlite, bainite, and martensite is present in the rebar as will be seen in Section 3.1. Only longitudinal stresses were considered, but the criteria for plastic flow usually consider all the components of stress [16]. Furthermore, transformation plasticity effects that were neglected may have a significant influence on the residual stress distribution and should be examined [20]. In addition to the material parameters, the geometry of the ribs on the rebar and its surface finish also significantly influence the fatigue behavior [8]. Experimental determination of residual stresses, e.g., using X-ray diffraction, will reach their limitations for such complex surface geometry. Furthermore, the resolution is not high enough to measure the residual stresses at the foot of the ribs, which usually act as the origin of cracks in these bars. Hence, it is only through simulating the quenching process with the correct material parameters, material constitutive model, and rebar geometry that a better understanding of the process can be gained.

\subsection{Constitutive Modeling for Numerical Investigations of the Tempcore ${ }^{\mathrm{TM}}$ Process}

Since it is not feasible to inspect the transient stresses shown in Figure 2 by in-process measurements, numerical simulations play an important role in understanding the generation of residual stresses during the heat treatment and thereby potentially attain further optimization of the process parameters. Given the requirement to resolve the macro-geometry of the considered component within the spatial discretization, constitutive modeling for 
heat treatment simulations is often based on component-scale continuum formulations where the microstructure is accounted for only be means of volume proportions of the existing phases $[5,6,19,20]$. In the simplest scenario, this approach typically involves solving the following initial boundary value problems (IBVPs):

- The transient non-homogeneous isotropic heat equation governing heat conduction in the spatial domain $\Omega \in \mathbb{R}^{n}$ spanned by the solid and the temporal domain $\left[t_{0}, t_{\mathrm{e}}\right] \subset \mathbb{R}$ with prescribed surface convection on $\partial \Omega$ and a known initial temperature field $T_{0}(\mathbf{x})[21]:$

$$
\begin{array}{rlrl}
\rho c_{\mathrm{p}} \frac{\partial T(\mathbf{x}, t)}{\partial t} & =\nabla \cdot(\lambda \nabla T(\mathbf{x}, t))+\dot{q} & \forall(\mathbf{x}, t) \in \Omega \times\left[t_{0}, t_{\mathrm{e}}\right] \\
-\lambda \nabla T(\mathbf{x}, t) & =h\left(T(\mathbf{x}, t)-T_{\infty}(\mathbf{x}, t)\right) & \forall(\mathbf{x}, t) \in \partial \Omega \times\left[t_{0}, t_{\mathrm{e}}\right] \\
T(\mathbf{x}, t)=T_{0}(\mathbf{x}) & \forall(\mathbf{x}, t) \in \Omega \times\left\{t_{0}\right\}
\end{array}
$$

Here, $\rho, c_{p}$, and $\lambda$ denote the density, specific heat capacity, and thermal conductivity of the compound, respectively, $T_{\infty}$ the coolant temperature, $h$ the heat transfer coefficient, and $\dot{q}$ the internal heat generation, e.g., due to latent heat associated with phase transformations or plastic dissipation.

- The mechanical compatibility and (quasi-)static equilibrium equations [21] where geometric linearity and negligence of body forces are typically suitable assumptions for heat treatment simulations [20]:

$$
\begin{aligned}
\boldsymbol{\epsilon}(\mathbf{x}, t)=\frac{1}{2}\left(\nabla \mathbf{u}(\mathbf{x}, t)+(\nabla \mathbf{u}(\mathbf{x}, t))^{T}\right), \quad \nabla \cdot \sigma(\mathbf{x}, t)=\mathbf{0} & \forall(\mathbf{x}, t) \in \Omega \times\left[t_{0}, t_{\mathrm{e}}\right] \\
\sigma(\mathbf{x}, t)=\sigma(\boldsymbol{\epsilon}(\mathbf{x}, t), t) & \forall(\mathbf{x}, t) \in \Omega \times\left[t_{0}, t_{\mathrm{e}}\right]
\end{aligned}
$$

In this system, $\sigma$ denotes the Cauchy stress tensor, $\epsilon$ the linear strain tensor, and $\mathbf{u}$ the displacement field. Equations (4) and (5) are usually complemented with displacement- or traction-free boundary conditions on a partition $\partial \Omega_{\mathbf{u}} \cup \partial \Omega_{\sigma}=\partial \Omega$ of the solid's boundary (the outward normal of which is denoted as $\mathbf{n}$ ) as well as stressand displacement-free initial conditions:

$$
\begin{array}{rrrrl}
\mathbf{u}(\mathbf{x}, t)=\mathbf{0} & \forall(\mathbf{x}, t) \in \partial \Omega_{\mathbf{u}} \times\left[t_{0}, t_{\mathrm{e}}\right], & \sigma(\mathbf{x}, t) \cdot \mathbf{n}(\mathbf{x}, t)=\mathbf{0} & \forall(\mathbf{x}, t) \in \partial \Omega_{\sigma} \times\left[t_{0}, t_{\mathrm{e}}\right] \\
\mathbf{u}(\mathbf{x}, t)=\mathbf{0} & \forall(\mathbf{x}, t) \in \Omega \times\left\{t_{0}\right\}, & \sigma(\mathbf{x}, t)=\mathbf{0} & \forall(\mathbf{x}, t) \in \Omega \times\left\{t_{0}\right\}
\end{array}
$$

To complete the description of the mechanical IBVP, a constitutive model that particularizes Equation (5) must be specified, where the assumption of isotropic thermoelasto-plastic behavior according to the classical flow theory of plasticity is almost universal in literature [20]. This amounts to computing the stresses $\sigma$ from the elastic strains $\epsilon^{\mathrm{e}}$ as

$$
\sigma=\mathbb{C}: \epsilon^{\mathrm{e}}=\left(\frac{v E}{(1+v)(1-2 v)} \mathbf{I} \otimes \mathbf{I}+\frac{E}{(1+v)} \mathbb{I}\right):\left(\boldsymbol{\epsilon}-\boldsymbol{\epsilon}^{\mathrm{th}}-\boldsymbol{\epsilon}^{\mathrm{p}}\right)
$$

where $\epsilon^{\text {th }}$ is the eigenstrain due to thermal expansion (and potentially phase transformations) and $\epsilon^{\mathrm{P}}$ is the plastic strain computed by integration of the (associated) flow rule

$$
\dot{\boldsymbol{\epsilon}}^{\mathrm{p}}=\gamma \frac{\partial f(\sigma)}{\partial \sigma}
$$

subject to the constraints $\gamma \geq 0, f(\sigma)=\sqrt{\frac{3}{2} \sigma^{\prime}: \sigma^{\prime}}-\sigma^{\mathrm{Y}} \leq 0$ (von Mises criterion) and $\gamma f(\sigma)=0$ [16]. In these equations, $\mathbf{I}$ and $\mathbb{I}$ denote the identity tensors of rank 2 and 4 , respectively, $\sigma^{\prime}$ the stress deviator, $\gamma$ the plastic multiplier, $\sigma^{\mathrm{Y}}$ the yield strength, and $E$ and $v$ Young's modulus and the Poisson's ratio, respectively. 
In order to apply the above IBVPs to the numerical simulation of heat treatment of a solid compound of more than one phase, the material parameters encountered in above equations are most commonly computed via a linear volume-fraction averaged mixture rule from the respective parameters of the individual phases [20]. For example, the yield strength $\sigma^{\mathrm{Y}}$ of a mixture of $P$ phases, each constituting a volume fraction $z_{i}=V_{i} V^{-1}$, $i=1 \ldots P$, of the microstructure at the considered point $\mathbf{x} \in \Omega$ of the continuum, may be assumed to adhere to

$$
\sigma^{\mathrm{Y}}=\sum_{i=1}^{P} z_{i} \sigma_{i}^{\mathrm{y}}
$$

where $\sigma_{i}^{\mathrm{y}}$ denotes the yield strength of phase $i$. Furthermore, evolution equations describing the phase transformation kinetics in terms of the volume fractions $z_{i}$ of each phase are required to evaluate such mixture rules.

It is apparent from the above presentation that any numerical computation of processinduced residual stresses based on a thermo-mechanical constitutive model of comparable complexity as above relies on the accurate identification of at least the following parameters for each phase encountered during the process: density, heat capacity, and conductivity for the heat transfer problem and Young's modulus, Poisson's ratio, and the yield strength for the mechanical problem. The aim of this paper is therefore to enable numerical heat-treatment simulations for rebars by experimental determination of the mechanical parameters for the alloy B500B.

\section{Materials and Methods}

Rebars are made from low-carbon steels with very little amounts of other alloying elements. The specimens for the studies were extracted from B500B rebar samples [22] with a nominal diameter of $28 \mathrm{~mm}$ obtained from industry partners. The chemical composition of the samples was measured by spectrometry on the cross-sections of the rebars. The carbon composition of the alloy varied between $0.17 \%$ and $0.23 \%$ between various samples. The mean chemical content from four rebar samples analyzed and the mean is listed in the last line of Table 1 . Trace amounts of other elements less than $0.01 \%$ are not displayed.

Table 1. Chemical composition of four rebar samples and the mean value (wt \%). The balance is Fe.

\begin{tabular}{cccccccc}
\hline $\mathbf{C}$ & $\mathbf{S i}$ & $\mathbf{M n}$ & $\mathbf{C u}$ & $\mathbf{N i}$ & $\mathbf{C r}$ & $\mathbf{P}$ & $\mathbf{S}$ \\
\hline 0.17 & 0.25 & 0.79 & 0.37 & 0.12 & 0.07 & 0.01 & 0.04 \\
0.19 & 0.28 & 0.80 & 0.37 & 0.13 & 0.08 & 0.03 & 0.05 \\
0.19 & 0.23 & 0.84 & 0.25 & 0.12 & 0.09 & 0.01 & 0.03 \\
0.23 & 0.29 & 0.88 & 0.24 & 0.11 & 0.10 & 0.00 & 0.04 \\
\hline 0.19 & 0.26 & 0.83 & 0.31 & 0.12 & 0.09 & 0.02 & 0.04 \\
\hline
\end{tabular}

\subsection{Tensile Tests at Elevated Temperatures}

The yield stress of individual phases are essential in modeling the residual stresses as described in Section 1.1. The tensile tests were carried out in a quenching and deformation dilatometer, Dil805 A/D/T from Baehr Thermoanalyse (TA Instruments). The flat specimens used for the tensile tests had a geometry as shown in Figure 3. The temperatures at which the phases were tested were chosen according to the temperatures the individual phases experience during the Tempcore ${ }^{\mathrm{TM}}$ process. As shown in Figure 1, the martensite that is generated during the initial quenching step sustains from $200^{\circ} \mathrm{C}$ up to $600{ }^{\circ} \mathrm{C}$ in the following tempering step. The austenite in the core experiences slow cooling and would start transforming at $\mathrm{A}_{\mathrm{c} 3}$; hence, it was tested in the temperature regime above and slightly below $\mathrm{A}_{\mathrm{c} 3}[2,19,23]$.

The reason for using the dilatometer instead of a conventional tensile testing machine is the fast inductive heating in the dilatometer, which allows the specimens to be heated quickly to the testing temperature. This is important because the specimens have to be 
tested at some temperatures where the phases are unstable and will start transforming. In the conventional tensile testing machine with an oven, the specimen has to be held at the testing temperature for approx. $30 \mathrm{~min}$ to reach a homogeneous temperature distribution. This would lead to substantial tempering of the martensite [24]. In the dilatometer the specimens were inductively heated at ca. $10 \mathrm{~K} \mathrm{~s}^{-1}$ to the testing temperature, and the strain rate was $0.02 \mathrm{~s}^{-1}$. This allowed the specimens to be tested within two minutes.

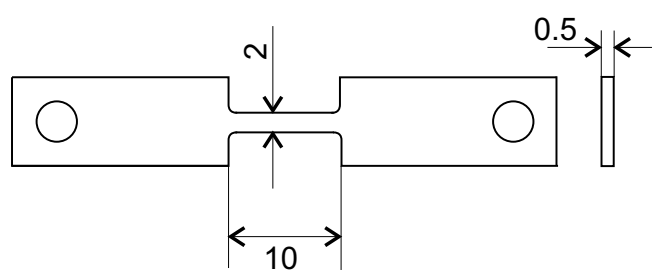

Figure 3. The geometry of the flat specimen used for the tensile tests using a deformation dilatometer (dimensions in $\mathrm{mm}$ ).

In order to obtain the stress-strain curve of austenite, a thermocouple was tack welded in the middle of the specimens, where the temperature reaches its maximum. After mounting the specimens in the dilatometer, they were heated above $A_{c 3}$ to $850{ }^{\circ} \mathrm{C}$ for $60 \mathrm{~s}$ to ensure homogeneous austenitization. Thereafter they were quickly cooled with a cooling rate of ca. $100 \mathrm{~K} \mathrm{~s}^{-1}$ to the testing temperature and tested.

To investigate the martensitic phase, specimens were first austenitized by soaking in a heat treatment oven at $850^{\circ} \mathrm{C}$ for $30 \mathrm{~min}$ and afterwards water-quenched, since the quenching rate in the dilatometer was insufficient for in situ transformation to a fully martensitic state. The Vickers hardness of these quenched specimens exceeded 500 HV30, which corresponds to a fully martensitic structure [25]. Thereafter, isothermal tensile tests were conducted at various temperatures reached with a heating rate of $10 \mathrm{~K} \mathrm{~s}^{-1}$. The tests lasted ca. $2 \mathrm{~min}$, including heating the specimen from room temperature to the testing temperature. In practice, the tempering time is directly proportional to the mass of the workpiece [26]. Since the specimens are thin sheets of metal, they are likely to be tempered to some extent even within the duration of testing $[27,28]$. Tempering, however, also occurs during the Tempcore ${ }^{\mathrm{TM}}$ process when the martensite in the surface region is heated up; therefore, the results of the experiments are still relevant to the process.

\subsection{Elastic Constants}

Determining the Young's modulus $E$ using the stress-strain curve is erroneous given the maximum length of the tensile specimen in the dilatometer is only $10 \mathrm{~mm}$. Impulse Excitation Technique (IET) is a precise and reliable measuring method for the determination of elastic properties. The sound waves emitted from a free vibrating specimen are recorded by a sensitive microphone, allowing to evaluate the fundamental resonant frequencies [29]. In case of metallic alloys the resonance frequencies depend mainly on the geometry of the specimen, the elastic properties, and the density of the material. By analysis of simple geometries, such as cylinders or rectangular bars with respect to the fundamental flexural eigenfrequency, it is possible to calculate the Young's modulus in case of homogeneous and isotropic elastic properties by analytical approaches provided by the ASTM-standard [30]. The simplicity of the experimental set-up allows to perform the measurements at room temperature as well as at elevated temperatures.

The specimens were rectangular prisms with dimensions of $60 \times 15 \times 4 \mathrm{~mm}^{3}$. A standard specimen with the ferritic-pearlitic microstructure and a hardened specimen with martensitic microstructure were measured using a single specimen. To achieve this, the measurements were done while heating a hardened specimen from room temperature to $900{ }^{\circ} \mathrm{C}$ and also measured while slowly cooling it down after 5 min of soaking to let it austenitize completely. For hardening the specimen, it was austenitized in a heat treatment oven at $860{ }^{\circ} \mathrm{C}$ for $30 \mathrm{~min}$ and then quenched in water. Then Young's modulus was measured while 
heating from room temperature at a rate of $16 \mathrm{~K} \mathrm{~min}^{-1}$ and while slowly cooling down at $5 \mathrm{Kmin}^{-1}$.

Following the ASTM-standard, the Young's modulus is calculated by

$$
E=0.9465\left(\frac{m f_{\mathrm{f}}^{2}}{b}\left(\frac{L^{3}}{t^{3}}\right)\right) T_{1},
$$

where $l$ is the length, $b$ the width, and $t$ the thickness of the specimen. The specimen mass is denoted by $m$ and the measured fundamental flexural resonance frequency by $f_{\mathrm{f}}$. The formula is based on Euler-Bernoulli beam theory, whereby the correction factor $T_{1}$ accounts for the finite thickness of the specimen.

A sensitivity analysis of Equation (11) shows that the calculated Young's modulus is highly sensitive to the specimen thickness. It is challenging to evaluate the thickness exactly due to the distortion caused during the quenching. Hence, the specimen was subsequently ground with sand paper by hand in order to remove the slight curvature. Finally, the dimensions of the specimen were measured by use of a high precision micrometer screw at six different positions for determining its thickness and width and at three positions for the determination of its length.

\subsection{Residual Stresses}

Residual stress measurement techniques fall mainly into either of the two categories of destructive or non-destructive methods. Destructive techniques include sectioning, hole drilling, nanoindentation, cut compliance methods, etc. [31-34]. The fundamental concept behind these techniques is to mechanically remove a section of the workpiece by slitting or sectioning and measure the resulting deformation, usually using strain gauges, and then reconstruct the initial residual stress field. Non-destructive methods include diffraction using X-ray or thermal neutrons from reactors. The principle is to use the lattice structure of crystalline materials as an intrinsic strain gauge. $X$-rays generated in the lab using standard X-ray sources have an attenuation length of a few micrometers, whereas X-rays from synchrotron sources and neutrons can penetrate the material up to a 7-8 $\mathrm{mm}[35,36]$.

The near-surface residual stresses in this work were measured by X-ray diffraction (XRD) using the device Xstress3000 with a G2R goniometer from the manufacturer stresstech (Vaajakoski, Finland). The experimental parameters for the stress measurements with XRD are shown in Table 2. The residual stresses were measured in between the non-uniform ribs of the rebars using the $\sin ^{2} \psi$ method [36,37]. The penetration depth of the $\mathrm{Cr} \mathrm{K}_{\alpha}$ radiation was calculated to be $11 \mu \mathrm{m}$ in this alloy using the software xraylib [38]. Thus, the effective depth of measurement is about half of that, i.e., $5 \mu \mathrm{m}$ when the radiation is directed perpendicular to the surface. The in-depth stress profile was determined by removing thin layers of material using electrochemical etching and measuring the stresses on the new surface using XRD. The depth increment was measured using a high-precision dial gauge with a resolution of $1 \mu \mathrm{m}$. Due to the roughness on the etched surface and the need to remove the specimen between etching and measuring steps, the accuracy reduced so that the realistic accuracy was ca. $10 \mu \mathrm{m}$. The stress relaxation due to the removal of layers was corrected by using the stresses measured before the removal and the amount of material removed. The foundations for these corrections were laid by Moore and Evans [39] and are integrated into the software of the Xstress device. 
Table 2. X-ray diffraction parameters for measuring residual stresses.

\begin{tabular}{ll}
\hline Radiation & $\mathrm{Cr} \mathrm{K}_{\alpha}$ \\
Wavelength & $0.229 \mathrm{~nm}$ \\
Spot size & $1 \mathrm{~mm}$ \\
Voltage & $30 \mathrm{kV}$ \\
Current & $8 \mathrm{~mA}$ \\
Exposure time & $80 \mathrm{~s}$ \\
Tilt angles, $\psi$ & $\pm 42^{\circ}, \pm 35.4^{\circ}, \pm 28.2^{\circ}, \pm 19.5^{\circ}, 0^{\circ}$ \\
Bragg angle, $2 \theta$ & $156.4^{\circ}$ \\
Young's modulus & $206.6 \mathrm{GPa}$ (cf. Section 3.3) \\
Poisson's ratio & 0.273 (cf. Section 3.3) \\
Diffracting plane & Ferrite (211) \\
\hline
\end{tabular}

\section{Results and Discussion}

\subsection{Micro-Hardness and Metallography}

The micro-hardness profile along the radius of the rebar shown in Figure 4 gives a good picture of the effect of the heat treatment process that the material has undergone. It is further useful to check if the product meets the tolerances specified and to compare the specimens with specific microstructures produced by heat treating in the lab [40]. The micro-hardness was measured using a LECO Micro-Hardness tester with a load of $500 \mathrm{~g}$ and a dwell time of $15 \mathrm{~s}$.

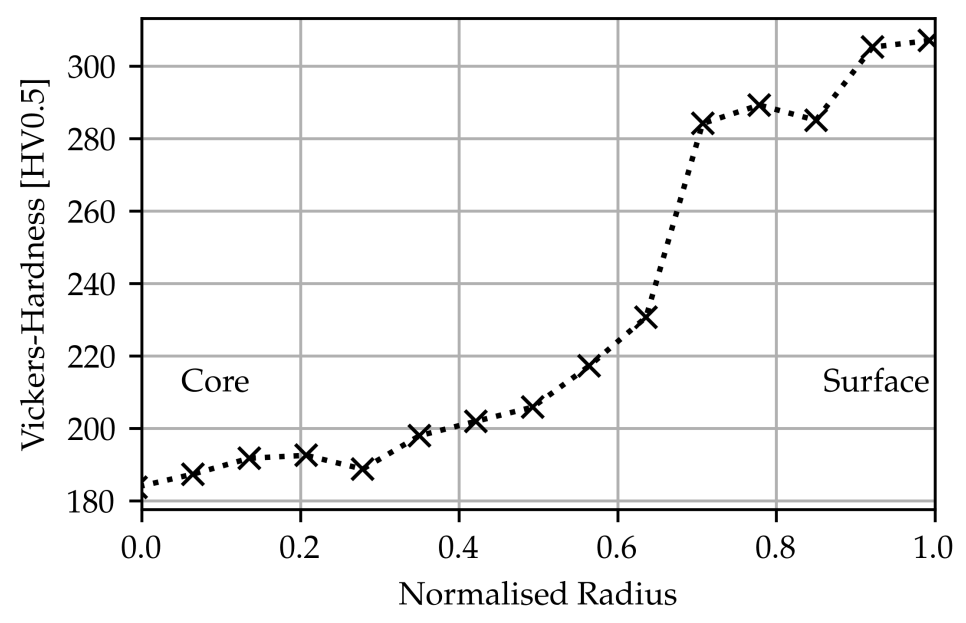

Figure 4. Hardness profile along the radius of the rebar.

The microstructure was investigated in the transverse as well as in the longitudinal cross-section of the rebar, which after polishing were etched with Nital for optical microscopy. Figure 5 shows the microstructures observed at different positions on the transverse cross-section of the rebar. On the top of Figure 5 where the positions of the individual microstructures are marked, a clear demarcation can be seen about $3 \mathrm{~mm}$ beneath the surface of the rebar. The core shows a mixture of ferrite and pearlite whereas near the surface tempered martensite can be seen inside prior austenite grains. In the transition zone where the cooling rate was not fast enough for martensite formation, a bainitic microstructure is observed. The microstructures obtained from the longitudinal cross-section were similar to those of the transverse cross-section and are not shown here. The longitudinal cross-section was further used to investigate any difference in microstructure on either sides of the transverse ribs that might have arisen due to the water being sprayed from one direction only inside the quenching chamber of the manufacturing unit. No differences were observed in the grain sizes, hardness, as well as in the thickness of the tempered martensite layer. 


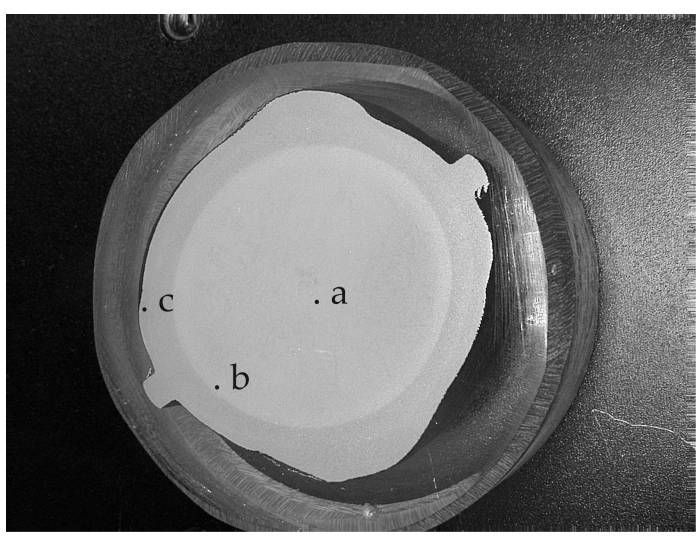

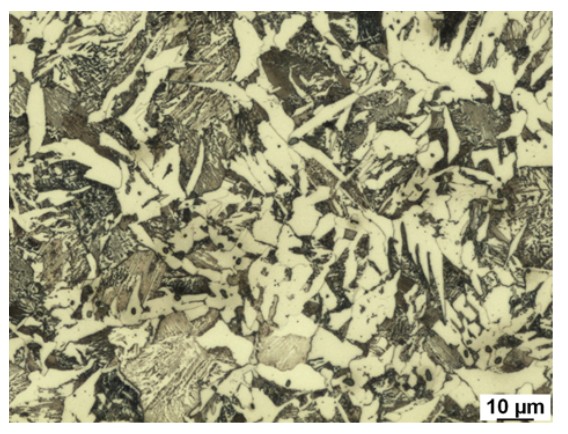

(a) Ferritic pearlitic microstructure in the core of the rebar

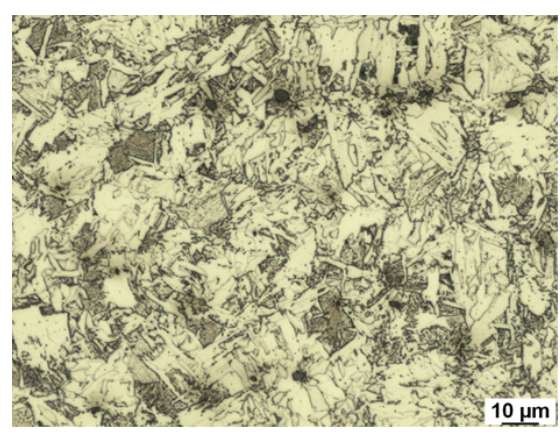

(b) Bainitic microstructure in the transition zone between the surface and core of the rebar

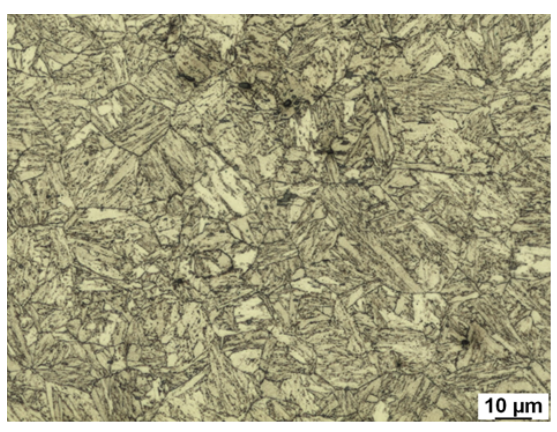

(c) Tempered martensite in prior austenite grains near the surface of the rebar

Figure 5. Microstructures observed in the cross-section of the rebar ranging from slowly cooled ferrite to tempered martensite.

\subsection{Tensile Tests at Elevated Temperatures}

The stress-strain curves as a function of temperature are shown in Figure 6. The martensite specimens were deformed up to fracture (Figure 6a), whereas for the austenite samples the elongation at fracture could not be determined since it is beyond the limit of admissible elongations of the displacement sensor of the dilatometer. Testing austenite at $700{ }^{\circ} \mathrm{C}$ did not result in reliable data, since it was not possible to avoid its transformation into ferrite and pearlite. A higher strain rate of $0.05 \mathrm{~s}^{-1}$ during the tensile test was also tried to shorten the testing time, but it had no effect as the recorded stress-strain curve was very similar to the one shown in Figure 6b; therefore, the decomposition of austenite could not be avoided since it occurs within $5 \mathrm{~s}$. The yield stress $R_{\mathrm{p} 0.2}$ and the ultimate tensile strength $R_{\mathrm{m}}$ from each curve is listed in Table 3. The temperature-dependent Young's moduli determined using the resonance frequency measurements, shown in Figure 7, were utilized in order to deduce the $R_{\mathrm{p} 0.2}$ from the stress-strain curves.

The yield stress of austenite at temperatures above $A_{c 3}$ ranges from 37 to $77 \mathrm{MPa}$. This is very low compared to the shrinkage stresses that are generated during quenching. Referring back to the discussion in Section 1.1 and Figure 2a, it can be seen that the austenite in the surface region and in the core would undergo a large amount of plastic deformation during quenching.

The hardness of the martensitic specimens after the tensile test was around $200 \mathrm{HV} 30$, which corresponds to tempered martensite. The same values were also observed in the near-surface tempered martensite region of the rebar in Figure 4. Thus, it was not possible to avoid the tempering of the martensite during the tensile test, although the duration of the test was kept as short as possible. At high temperatures, the migration of carbon atoms started within seconds, followed by precipitation of transient iron carbides in the first few minutes [28]. Consequently, the martensitic specimen gained substantial ductility at the higher temperatures, as seen in Figure 6a. 
The tensile test at room temperature was conducted in the universal tensile testing machine on a standard cylindrical specimen. The extensometer was removed after reaching $R_{\mathrm{p} 0.2}$, and the strain until fracture was evaluated on the basis of the crosshead displacement. The specimen tested at $300^{\circ} \mathrm{C}$ in the dilatometer also had a slightly smaller cross-section and shorter length than the other flat specimens. Due to these different specimen geometries, the elongation values from these tests are not directly comparable to the other tests when strain localizes beyond uniform elongation.

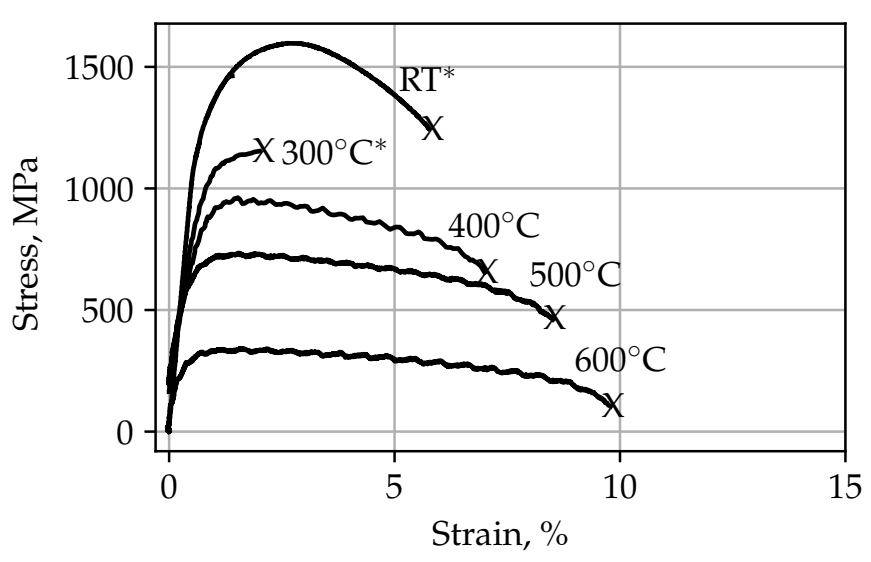

(a) (Tempered) Martensite

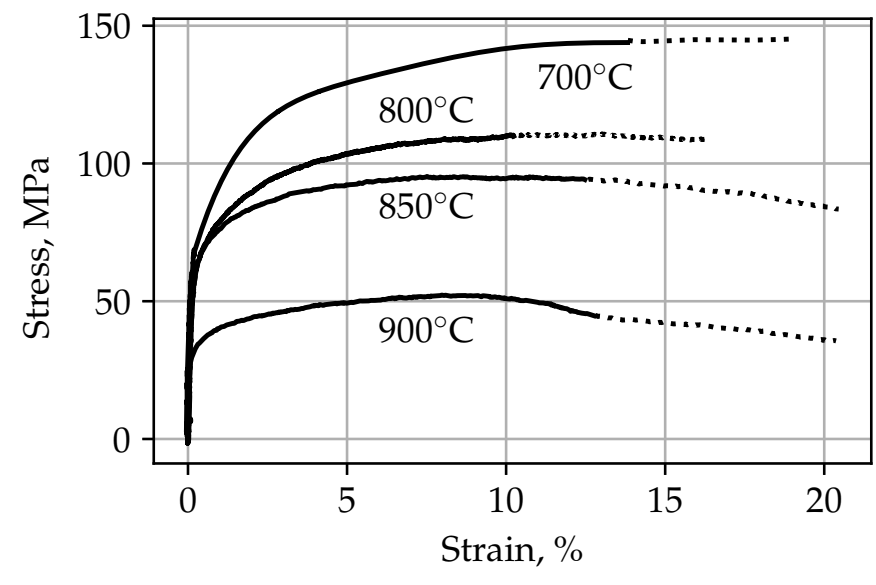

(b) Austenite

Figure 6. Stress-strain curves at different temperatures. ${ }^{*}$ Different geometry of the specimens tested at room temperature (RT) and $300^{\circ} \mathrm{C}$.

Table 3. Yield stress and tensile strength of martensite and austenite at elevated temperatures.

\begin{tabular}{cccc}
\hline & $\mathbf{T}$ in ${ }^{\circ} \mathbf{C}$ & $\boldsymbol{R}_{\mathbf{p 0 . 2}}$ in $\mathbf{M P a}$ & $\boldsymbol{R}_{\mathbf{m}}$ in $\mathbf{~ M P a}$ \\
\hline & $\mathrm{RT}$ & 1290 & 1598 \\
(Tempered) Martensite & 300 & 940 & 1150 \\
& 400 & 770 & 960 \\
& 500 & 650 & 730 \\
Austenite & 600 & 280 & 340 \\
& 700 & 92 & 145 \\
& 800 & 77 & 110 \\
& 850 & 74 & 90 \\
& 900 & 37 & 52 \\
\hline
\end{tabular}

\subsection{Elastic Constants}

The Young's modulus, bulk modulus, and Poisson's ratio were determined for the base material (ferritic+pearlitic microstructure) at room temperature and were 206.6 GPa, 81.26 GPa, and 0.273, respectively, which corresponds to literature data [41]. The measured Young's moduli over the temperature range of $25-900{ }^{\circ} \mathrm{C}$ for the specimen with initial martensitic and ferritic-pearlitic microstructures are shown in Figure 7. Both the specimens undergo phase transformation between $\mathrm{A}_{\mathrm{c} 1}$ and $\mathrm{A}_{\mathrm{c} 3}$, which can be seen as a pronounced decrease in Young's modulus above about $700{ }^{\circ} \mathrm{C}$. Young's modulus of austenite remains almost constant up to $900^{\circ} \mathrm{C}$. 


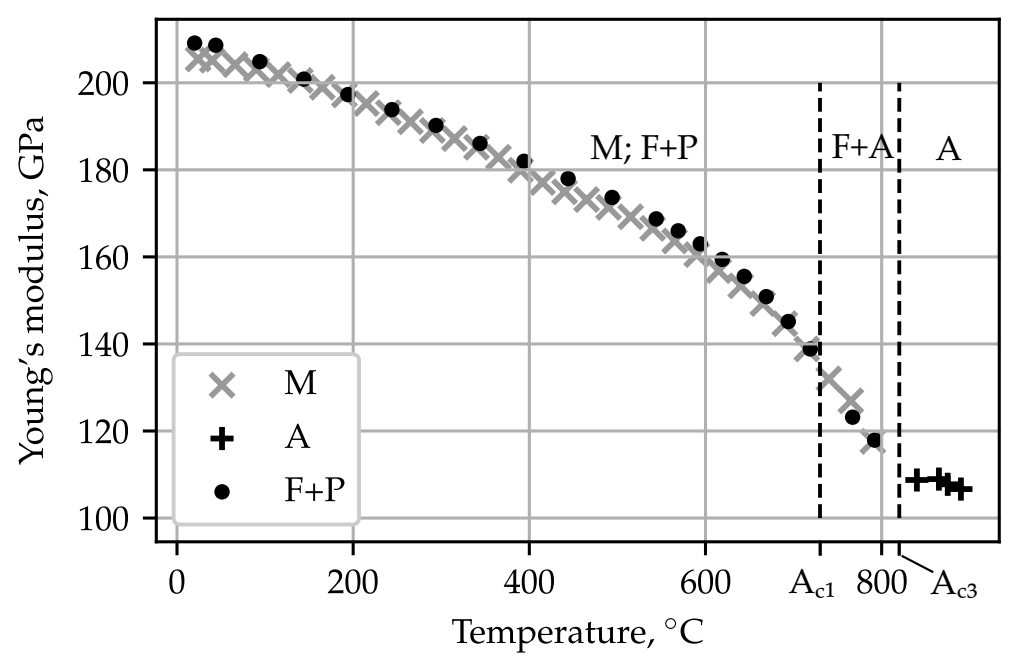

Figure 7. Young's modulus as a function of temperature. M: martensitic (tempered martensitic) initial microstructure $(\times), \mathrm{F}+\mathrm{P}$ : ferritic-pearlitic initial microstructure $(\bullet)$, A: pure austenite $(+)$.

The furnace was purged with argon gas while heating up to reduce the oxidation of the samples at high temperatures. Practically the oxidation cannot be completely prevented, which leads to changes in the specimen dimensions and their mass during the experiment, which causes uncertainties in the calculated Young's modulus. Thickness and mass were also measured after the experiment to determine the thickness of the oxide layer. Overall, this effect can lead to an error of up to $\pm 4 \mathrm{GPa}$ in $E$. The same experiment was performed for a specimen with initial ferritic-pearlitic microstructure in order to check for differences resulting from the two variants of the initial microstructure. It turned out that these differences were in range of the estimated uncertainty.

\subsection{Continuous Cooling Transformation Diagram}

The continuous cooling transformation (CCT) diagram for the particular alloy is indispensable for studying its transformation characteristics. The diagram shown in Figure 8 is taken from literature [42] and published here with the authors' permission. The chemical composition of the alloy of the diagram is compared to the rebar composition in Table 4. It should be noted that both the carbon content of the tested rebars $(0.17 \%$ to $0.23 \%$ wt $\%$ (cf. Table 1)) and the content of Mn and Si matched the composition of the CCT-steel quite well. Hence, it is reasonable to assure that depicted CCT diagram is relevant for the rebar steel studied in this work. Furthermore, three heating and cooling schedules for the rebar steel were realized with different cooling rates and were compared with the CCT diagram as shown in Table 5. The hardness of the specimens from this heat treatment corresponding to the ones in the CCT diagram are shown in Figure 8 as a, b, and c. During heating, the temperatures $A_{c 1}$ and $A_{c 3}$ agreed with those noted in the diagram $715^{\circ} \mathrm{C}$ and $835^{\circ} \mathrm{C}$, respectively. During cooling, the starting and finishing temperatures of the transformations, $T_{1}$ and $T_{2}$, and the hardness values at the end of the transformations showed good agreement with the values given in the CCT diagram. 


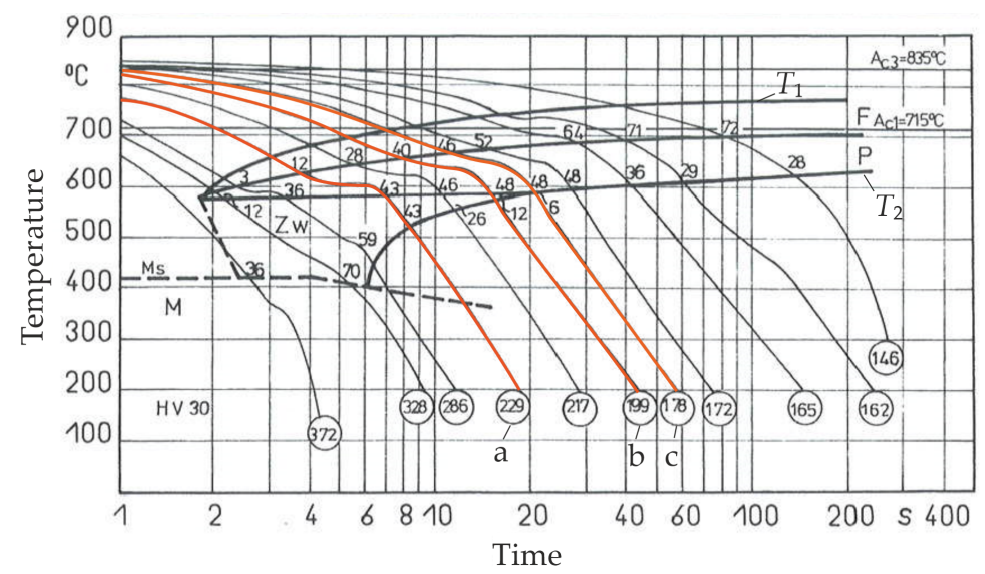

Figure 8. Continuous cooling transformation diagram for a composition matching the B500B rebar steel. Numbers in circles denote the Vickers hardness HV30. Reproduced by permission of the authors of [42].

Table 4. Chemical composition of the sample from the CCT diagram compared with that of the rebar $(w \mathrm{t} \%)[42]$.

\begin{tabular}{ccccccccc}
\hline & $\mathbf{C}$ & Si & Mn & Cu & Ni & Cr & P & S \\
\hline CCT & 0.19 & 0.29 & 0.67 & - & - & - & 0.007 & 0.011 \\
Rebar & 0.19 & 0.26 & 0.83 & 0.31 & 0.12 & 0.09 & 0.02 & 0.04 \\
\hline
\end{tabular}

Table 5. Comparison of dilatometric tests of rebar samples to the corresponding curves in the CCT diagram. Temperatures are given in ${ }^{\circ} \mathrm{C}$.

\begin{tabular}{cccccccccccc}
\hline & \multirow{2}{*}{$\mathbf{A}_{\mathbf{c 1}}$} & \multirow{2}{*}{$\mathbf{A}_{\mathbf{c} 3}$} & \multicolumn{3}{c}{$\mathbf{a}$} & \multicolumn{3}{c}{$\mathbf{b}$} & \multicolumn{3}{c}{$\mathbf{c}$} \\
\cline { 3 - 11 } & & & $\mathbf{H V 3 0}$ & $\boldsymbol{T}_{\mathbf{1}}$ & $\boldsymbol{T}_{\mathbf{2}}$ & HV30 & $\boldsymbol{T}_{\mathbf{1}}$ & $\boldsymbol{T}_{\mathbf{2}}$ & HV30 & $\boldsymbol{T}_{\mathbf{1}}$ & $\boldsymbol{T}_{\mathbf{2}}$ \\
\hline CCT & 715 & 835 & 229 & 650 & 520 & 199 & 690 & 570 & 178 & 715 & 590 \\
Rebar & 730 & 820 & 235 & 610 & 531 & 192 & 676 & 564 & 177 & 700 & 600 \\
\hline
\end{tabular}

\subsection{Residual Stresses}

The near-surface residual stresses in the rebar were measured at the location between two transverse non-parallel ribs and are shown in Figure 9. Both the longitudinal (axial) and tangential stresses are compressive, and they vary in magnitude almost in a linear fashion from $10 \mathrm{MPa}$ on the surface to $90 \mathrm{MPa}$ up to a depth of $100 \mu \mathrm{m}$. Beyond this depth the magnitude remains the same for up to a depth of about $300 \mu \mathrm{m}$. Compressive stresses of about $50 \mathrm{MPa}$ near the surface of the rebar were also observed by Rocha et al. [10], but were documented only to a depth of $50 \mu \mathrm{m}$. The stresses shown in Figure 9 are compressive and much lower than the tensile yield strength of tempered martensite at room temperature, which is the predominant microstructure constituent near the surface of the rebar. No stress reversal of compressive to tensile stresses was observed in the studied depth range. The measurement uncertainty depicted is evaluated in the course of the linear regression analysis of the lattice spacing to the $\sin ^{2} \psi$ values according to the $\sin ^{2} \psi$-method [36,43]. 


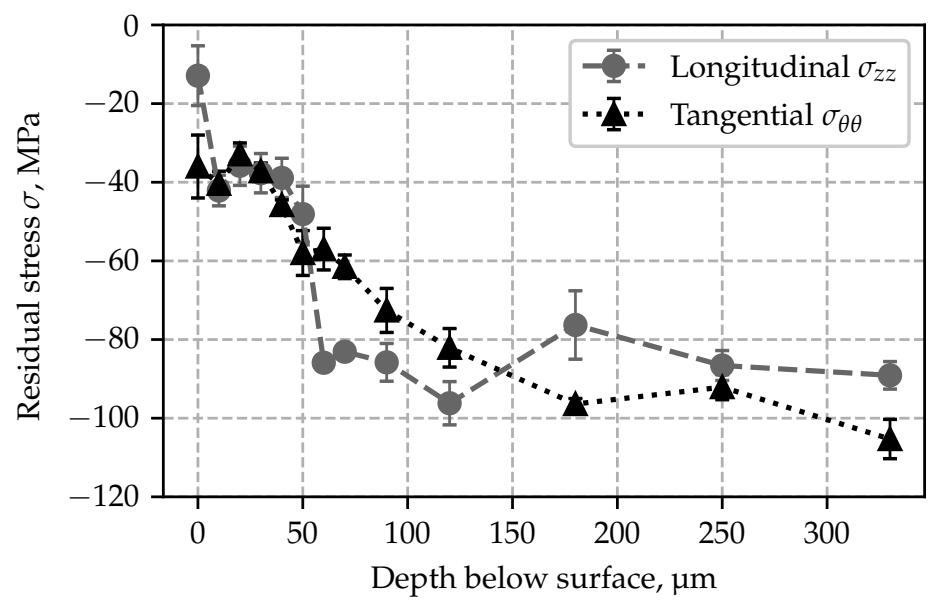

Figure 9. The residual stress near the surface of the rebar measured using X-ray diffraction.

\section{Summary}

Conclusive studies on the generation and distribution of residual stresses in rebars manufactured through the Tempcore ${ }^{\mathrm{TM}}$ process are still lacking in literature. To help understand the phenomena contributing to the residual stress generation by means of numerical simulations, the parameters of the underlying thermo-mechanical constitutive model have to be determined. In this contribution, the parameters needed for the rebar alloy B500B were characterized as follows:

1. The source of residual stresses was clarified, and the necessary material parameters for modeling stress distribution were identified.

2. Metallographic analysis and micro-hardness measurements of the rebar across the cross-section were performed. Tensile tests were conducted to characterize the mechanical parameters of individual phases of the rebar, viz. austenite and (tempered) martensite, as a function of temperature.

3. The elastic constants were determined using the resonance frequency method to obtain more accurate values than from the tensile tests. The results were also presented as a function of temperature. It was seen that there is a negligible difference in Young's modulus between different phases below $\mathrm{A}_{\mathrm{c} 1}$.

4. The CCT diagram was identified and presented for the specific alloy of the rebar that is necessary for further investigations in which phase transformation kinetics are to be considered. The relevance of the diagram matched well with the chemical composition of the alloy as well as results from dilatometric investigations.

5. Residual stress distribution at the surface and in the subsurface region of the rebar were characterized using X-ray diffraction. The stresses were compressive with a magnitude of about $40 \mathrm{MPa}$ near the surface and about $100 \mathrm{MPa}$ beyond a depth of $100 \mu \mathrm{m}$. Stresses did not reverse their sign in the studied range of $300 \mu \mathrm{m}$ below the surface.

Author Contributions: Conceptualization, E.W., C.K.; software, C.H.W., T.R.; formal analysis, M.Z.S.H., C.H.W.; investigation, M.Z.S.H., C.H.W., T.R., S.R.; resources, S.R., K.O.; data curation, M.Z.S.H., T.O.; writing — original draft preparation, M.Z.S.H., C.H.W.; writing—review and editing, E.W.,C.K.; supervision, E.W., C.K., K.O.; project administration, E.W., C.K.; funding acquisition, E.W., C.K., K.O. All authors have read and agreed to the published version of the manuscript.

Funding: This research was funded by the Deutsche Forschungsgemeinschaft (DFG, German Research Foundation) under the project number 410264412.

Conflicts of Interest: The authors declare no conflict of interest. The funders had no role in the design of the study; in the collection, analyses, or interpretation of data; in the writing of the manuscript, or in the decision to publish the results. 


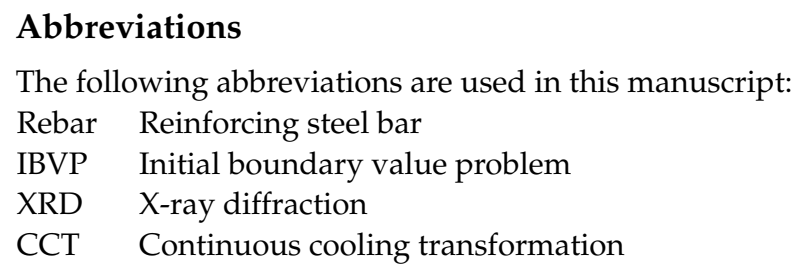

\section{References}

1. Noville, J.F. TEMPCORE, the most convenient process to produce low cost high strength rebars from 8 to $75 \mathrm{~mm}$. In Proceedings of METEC \& 2nd ESTAD 2015, European Steel Technology and Application Days, Düsseldorf, Germany, 15-19 June 2015.

2. Economopoulos, M.; Respen, Y.; Lessel, G.; Steffes, G. Application of the Tempcore process to the fabrication of high yield strength concrete-reinforcing bars. Metall. Rep. 1975, 45, 1-17.

3. Simon, P.; Economopoulos, M.; Nilles, P. Tempcore: A new process for the production of high-quality reinforcing bars. Iron Steel Eng. 1984, 61, 53-57.

4. Gehlen, C.; Osterminski, K.; Weirich, T. High-cycle fatigue behaviour of reinforcing steel under the effect of ongoing corrosion. Struct. Concr. 2016, 17, 329-337. [CrossRef]

5. Hosny, S.; Gepreel, M.A.H.; Ibrahim, M.G.; Bassuony, A.R. Simulation of Tempcore Process for 500 MPa Steel Bars. Met. Mater Int. 2020, 9, 2938. [CrossRef]

6. Bandyopadhyay, K.; Lee, J.; Shim, J.H.; Hwang, B.; Lee, M.G. Modeling and experiment on microstructure evolutions and mechanical properties in grade $600 \mathrm{MPa}$ reinforcing steel rebar subjected to TempCore process. Mater. Sci. Eng. A 2019, 745, 39-52. [CrossRef]

7. Bahleda, F.; Bujňáková, P.; Koteš, P.; Hasajová, L.; Novỳ, F. Mechanical Properties of Cast-in Anchor Bolts Manufactured of Reinforcing Tempcore Steel. Materials 2019, 12, 2075. [CrossRef]

8. Zheng, H.; Abel, A.A. Fatigue Properties of Reinforcing Steel Produced by TEMPCORE Process. J. Mater. Civ. Eng. 1999, 11, 158-165. [CrossRef]

9. Dotreppe, J.C.; Franssen, J.M.; Bruls, A.; Baus, R.; Vandevelde, P.; Minne, R.; Van Nieuwenburg, D.; Lambotte, H. Experimental research on the determination of the main parameters affecting the behaviour of reinforced concrete columns under fire conditions. Mag. Concr. Res. 1997, 49, 117-127. [CrossRef]

10. Rocha, M.; Brühwiler, E.; Nussbaumer, A. Geometrical and Material Characterization of Quenched and Self-Tempered Steel Reinforcement Bars. J. Mater. Civ. Eng. 2016, 28, 04016012. [CrossRef]

11. Kalpakjian, S.; Schmid, S.R.; Werner, E. Werkstofftechnik: Herstellung Verarbeitung Fertigung, 5th ed.; Pearson Deutschland GmbH: Hallbergmoos, Germany, 2011.

12. Repper, J.; Hofmann, M.; Krempaszky, C.; Regener, B.; Berhuber, E.; Petry, W.; Werner, E. Effect of macroscopic relaxation on residual stress analysis by diffraction methods. J. Appl. Phys. 2012, 112, 064906. [CrossRef]

13. Withers, P.J.; Bhadeshia, H. Residual stress. Part 1-Measurement techniques. Mater. Sci. Technol. 2001, 17, 355-365. [CrossRef]

14. Macherauch, E.; Vöhringer, O. Residual stresses after quenching. In Theory and Technology of Quenching; Liščić, B., Tensi, H.M., Luty, W., Eds.; Springer Science+Business Media, LLC: New York, NY, USA, 1992; pp. 117-181.

15. Tensi, H.M.; Stich, A.; Totten, G.E. Quenching and quenching technology. In Steel Heat Treatment: Metallurgy and Technologies; Totten, G.E., Ed.; CRC Press: Boca Raton, FL, USA, 2006; pp. 539-606.

16. de Borst, R.; Crisfield, M.A.; Remmers, J.J.; Verhoosel, C.V. Non-Linear Finite Element Analysis of Solids and Structures, 2nd ed.; Wiley Series in Computational Mechanics; Wiley: Chichester, UK, 2012.

17. Moyer, J.; Ansell, G. The volume expansion accompanying the martensite transformation in iron-carbon alloys. Metall. Trans. A 1975, 6, 1785-1791. [CrossRef]

18. Park, C.S.; Yi, H.J.; Kim, Y.T.; Han, S.W.; Lee, T.; Moon, Y.H. Tempcore Process Simulator to Analyze Microstructural Evolution of Quenched and Tempered Rebar. Appl. Sci. 2019, 9, 2938. [CrossRef]

19. Khalifa, H.; Megahed, G.; Hamouda, R.M.; Taha, M.A. Experimental investigation and simulation of structure and tensile properties of Tempcore treated rebar. J. Mater. Process. Technol. 2016, 230, 244-253. [CrossRef]

20. Simsir, C.; Gür, C.H. Simulation of quenching. Handb. Therm. Process. Model. Steels 2008, 342-426. [CrossRef]

21. Hughes, T.J. The Finite Element Method: Linear Static and Dynamic Finite Element Analysis; Courier Corporation: Washington, DC, USA, 2012.

22. DIN 488-1:2009-08. Reinforcing Steels_Part 1: Grades, Properties, Marking. 2009. Available online: https://infostore.saiglobal. com/en-us/standards/din-488-1-2009-387867_saig_din_din_880993/(accessed on 5 December 2020).

23. Park, C.S.; Van Tyne, C.J.; Lee, S.J.; Lee, T.; Kim, J.H.; Moon, Y.H. Prediction of Tempcore Rebar Strength Using a Thermomechanical Simulator with a Designed Hollow Specimen. Steel Res. Int. 2020, 91, 1900520. [CrossRef]

24. Speich, G.R.; Leslie, W.C. Tempering of steel. Metall. Trans. 1972, 3, 1043-1054. [CrossRef]

25. Canale, L.; Vatavuk, J.; Totten, G. 12.02-Introduction to Steel Heat Treatment. In Comprehensive Materials Processing; Hashmi, S., Batalha, G.F., Van Tyne, C.J., Yilbas, B., Eds.; Elsevier: Oxford, UK, 2014; pp. 3-37. [CrossRef]

26. Jost, S.; Langer, H.; Pietsch, D.; Uhlig, P. Rechnerische Ermittlung der Erwärmdauer bei der Wärmebehandlung von Stahl. Fert. Betrieb 1976, 26, 298-301. 
27. Canale, L.C.; Yao, X.; Gu, J.; Totten, G.E. A historical overview of steel tempering parameters. Int. J. Microstruct. Mater. Prop. 2008, 3, 474. [CrossRef]

28. Bhadeshia, H.K.D.H.; Honeycombe, R.W.K. Steels: Microstructure and Properties, 3rd ed.; Butterworth-Heinemann: Amsterdam, The Netherlands; London, UK, 2006.

29. Roebben, G.; Bollen, B.; Brebels, A.; van Humbeeck, J.; van der Biest, O. Impulse excitation apparatus to measure resonant frequencies, elastic moduli, and internal friction at room and high temperature. Rev. Sci. Instruments 1997, 68, 4511-4515. [CrossRef]

30. ASTM E1876-15. Standard Test Method for Dynamic Young's Modulus, Shear Modulus, and Poisson's Ratio by Impulse Excitation of Vibration. 2015, doi:10.1520/E1876-15. Available online: https:/ / www.astm.org/Standards/E1876.htm (accessed on 5 December 2020). [CrossRef]

31. Schajer, G.S., Ed. Practical Residual Stress Measurement Methods; John Wiley \& Sons, Ltd: Chichester, UK, 2013. [CrossRef]

32. Cheng, W.; Finnie, I. Residual Stress Measurement and the Slitting Method; Mechanical Engineering Series; Springer: New York, NY, USA, 2007.

33. Zhou, W.; Zhou, H.; Zhang, R.; Pei, Y.; Fang, D. Measuring residual stress and its influence on properties of porous $\mathrm{ZrO} 2 /(\mathrm{ZrO} 2+\mathrm{Ni})$ ceramics. Mater. Sci. Eng. A 2015, 622, 82-90. [CrossRef]

34. Volkwein, A.; Osterminski, K.; Meyer, F.; Gehlen, C. Distribution of residual stresses in reinforcing steel bars. Eng. Struct. 2020, 223, 111140, doi:10.1016/j.engstruct.2020.111140. [CrossRef]

35. Withers, P.J. Residual stress and its role in failure. Rep. Prog. Phys. 2007, 70, 2211-2264. [CrossRef]

36. He, B.B. Two-Dimensional X-ray Diffraction; Wiley Online Library: Hoboken, NJ, USA, 2009; Volume 2.

37. Wimmer, M.; Shahul Hameed, M.Z.; Wölfle, C.; Weisbrodt, V.; Zaeh, M.F.; Werner, E.; Krempaszky, C.; Semm, T. The influence of the process parameters on the surface integrity during peripheral milling of Ti-6Al-4V. TM-Technisches Messen 2020, 87, 721-731. [CrossRef]

38. Schoonjans, T.; Brunetti, A.; Golosio, B.; Sanchez del Rio, M.; Solé, V.A.; Ferrero, C.; Vincze, L. The xraylib library for X-ray-matter interactions. Recent developments. Spectrochim. Acta Part At. Spectrosc. 2011, 66, 776-784. [CrossRef]

39. Moore, M.; Evans, W. Mathematical correction for stress in removed layers in X-ray diffraction residual stress analysis. $S A E$ Trans. 1958, 340-345. [CrossRef]

40. Totten, G.E. Steel Heat Treatment: Metallurgy and Technologies; CRC Press: Boca Raton, FL, USA, 2006.

41. Köster, W.; Franz, H. Poisson's Ratio for Metals and Alloys. Metall. Rev. 1961, 6, 1-56. [CrossRef]

42. Seyffarth, P.; Meyer, B.; Scharff, A. Großer Atlas Schweiß-ZTU-Schaubilder, 2nd ed.; Fachbuchreihe Schweißtechnik, 0427-8682; DVS Media GmbH: Dusseldorf, Germany, 2018; Volume 110.

43. Lu, J. Handbook of Measurement of Residual Stresses; Fairmont Press: Lilburn, GA, USA, 1996. 